\title{
Carcinoma Cervix- Significance of Tumour Size in Treatment Outcome
}

\author{
Agarwal Amit ${ }^{1}$, Agrawal Gaurav², Kumar Piyush³ ${ }^{3}$ Sharma Manish Kumar4, Patneedi Bhavya ${ }^{5}$ \\ ${ }^{1}$ Senior Resident, Department of Radiation Oncology (Radiotherapy), Government Medical College, Shivpuri, Madhya \\ Pradesh, India. ${ }^{2}$ Consultant, Department of Surgical Oncology, BIMR, Gwalior, Madhya Pradesh, India. ${ }^{3}$ Professor and \\ HOD, Department of Radiation Oncology (Radiotherapy), SRMS, IMS, Bareilly, Uttar Pradesh, India. ${ }^{4}$ Senior Resident, \\ Department of Radiation Oncology (Radiotherapy), DSCI, New Delhi, India. ${ }^{5}$ Senior Resident, Department of Radiation \\ Oncology (Radiotherapy), GSL Medical College, Rajahmundry, Andhra Pradesh, India.
}

\section{ABSTRACT}

\section{BACKGROUND}

According to GLOBOCAN 2018, there will be an estimated 18.1 million new cancer cases and 9.6 million cancer deaths in 2018. Cancer of the cervix uteri is the fourth most frequently diagnosed cancer and fourth leading cause of cancer death in women worldwide after breast, colorectal and lung cancers. The worldwide incidence of cervical cancer is approximately 570,000 new cases annually, with approximately 311,000 deaths in 2018. More than $85 \%$ of the global burden occurs in the developing countries. In India, it is $16 \%$ of all cancers (ICMR). Many prognostic factors have been recognized in patients with cancer cervix that affects treatment outcome and causes failure. These have been divided into 1) patient related 2) tumour related and 3) treatment related factors. Patient related factors are- age, medical co-morbidities, renal status, blood haemoglobin level, HIV and HPV. Tumour related factors are- stage, lymph node involvement, parametrial extension, hydronephrosis, histology, grade and size of tumour. Treatment related factors are duration of treatment and total radiation dose and concurrent use of chemotherapy.

\section{METHODS}

This is a prospective observational study. Forty patients of carcinoma cervix were analysed from July 2014 to June 2016. All patients were planned for chemoradiation followed by brachytherapy. Clinical response was assessed (as per WHO criterion) during radiotherapy and every month after radiotherapy for at least 6 months. Collected data was analysed using standard statistical methods.

\section{RESULTS}

In this study, at the end of 6 months, out of a total of 40 cases studied, $75 \%$ of patients had complete response, $20 \%$ had partial response and $5 \%$ of patients had progressive disease. In this study, residual was observed in only one patient with volume of disease $<4 \mathrm{~cm}$ (in greatest dimension). Residual was observed in only one while in patients with volume of disease $\geq 4 \mathrm{~cm}$ residual was observed in $36 \%$ of patients. This difference in volume of disease for residual is statistically significant $(\mathrm{p}=0.038)$.

\section{CONCLUSIONS}

Tumour size has significant impact in treatment outcome of carcinoma cervix.
Corresponding Author:

Dr. Gaurav Agrawal, Consultant Surgical Oncology, BIMR, Gwalior, Madhya Pradesh, India. E-mail:drgauravagr1@gmail.com

DOI: $10.14260 / j e m d s / 2019 / 572$

Financial or Other Competing Interests: None.

How to Cite This Article:

Amit A, Gaurav A, Piyush $K$, et al. Carcinoma cervix - significance of tumour size in treatment outcome. J. Evolution Med. Dent. Sci. 2019;8(33):2629-2632, DOI: $10.14260 / j e m d s / 2019 / 572$

Submission 12-03-2019,

Peer Review 11-05-2019,

Acceptance 17-05-2019,

Published 19-08-2019.

\section{KEY WORDS}

$\mathrm{Ca}, \mathrm{Cx}$, Chemoradiation, Tumour Size, Carcinoma Cervix 


\section{BACKGROUND}

According to GLOBOCAN 2018, there will be an estimated 18.1 million new cancer cases and 9.6 million cancer deaths in 2018. Cancer of the cervix uteri is the fourth most frequently diagnosed cancer and fourth leading cause of cancer death in women worldwide after breast, colorectal and lung cancers. The worldwide incidence of cervical cancer is approximately 570,000 new cases annually, with approximately 311,000 deaths in $2018 .{ }^{1}$ Mortality rates of cervical cancer are substantially lower than incidence with a ratio of mortality to incidence to $50.3 \% .^{2}$ It is leading cause of cancer deaths in Sub-Saharan Africa and South Eastern Asia. More than $85 \%$ of the global burden occurs in the developing countries where it accounts for $13 \%$ of all the female cancers. $^{2}$ In India it is $16 \%$ of all cancers (ICMR). ${ }^{3}$ Cervical cancer is the second most common cancer in developing countries after carcinoma breast, but only the tenth most common in developed countries.

\section{Key Statistics in India. 4}

Women at risk for cervical cancer (Female Population Aged $\geq$ 15 yrs.)- 432.20 million. Annual number of cervical cancer cases- 1,22,844. Annual number of cervical cancer deaths67,477 . Crude incidence rates per 100,000 population per year- 20.2. Age-standardized incidence rate- 26.0.

Cervical cancer is rare in women under 30 yrs., of age and most common in women over 40 years, with the greatest number of deaths usually occurring in women in their $50 \mathrm{~s}$ and $60 \mathrm{~s},{ }^{5}$ with most women diagnosed in advanced stages. Major risk factors identified in epidemiologic studies are sex at a young age, multiple sexual partners, and promiscuous male partners, history of sexually transmitted diseases, poor genital hygiene and smoking. Cervical cancer results from genital infection with HPV (Human Papilloma Virus), which is a known human carcinogen.6,7 A large multinational cervical cancer studies found that more than $90 \%$ of all cervical cancers worldwide are caused by 8 HPV types: 16, 18, 31, 33, $35,45,52$, and 58 . Three types- 16,18 , and 45 - cause $94 \%$ of cervical adenocarcinomas. ${ }^{8}$ HIV (Human Immunodeficiency Virus) infection is associated with a 5 -fold increase in the risk of cervical cancer, presumably because of an impaired immune response to HPV infection. ${ }^{9}$ Women who have an affected first-degree biologic relative have a 2 -fold relative risk of developing a cervical tumour compared with women who have a non-biologic first-degree relative with a cervical tumour genetic susceptibility accounts for less than $1 \%$ of cervical cancers. Cervical cancers tend to occur most commonly at the squamo-columnar junction, which is an area of active proliferation and metaplasia and spreads to uterus, vagina, parametrium, lymph nodes and spread to lymph nodes is in fairly systemic order involving paracervical, parametrial followed by obturator (Medial external iliac) then involving iliac and para-aortic. About $85 \%$ of cervical cancers are squamous cell cancers and the remainder adenocarcinomas. Endometroid, small cell carcinoma, serous and clear cell carcinoma are rare histological variants of cervical cancer. Adenocarcinoma is reported four times more commonly than squamous carcinoma in cervical stumps. ${ }^{10}$ Many prognostic factors have been recognized in patients with cancer cervix that affects treatment outcome and causes failure. These have been divided into 1) patient related 2) tumour related and 3) treatment related factors. Patient related factors are- age, medical co-morbidities, renal status, blood haemoglobin level, HIV and HPV. Tumour related factors are- stage, lymph node involvement, parametrial extension, hydronephrosis, histology, grade and size of tumour. Treatment related factors are duration of treatment and total radiation dose and concurrent use of chemotherapy. ${ }^{11,12,13,14}$

Cervical cancer is clinically staged in accordance with the system of the International Federation of Gynecology and Obstetrics (FIGO). Classification is performed prior to treatment and based on clinical examination including examination under anaesthesia, colposcopy, biopsy, endocervical curettage, hysteroscopy, Cystoscopy, proctoscopy, intravenous urography and X-ray examination of the lungs and skeleton. The prognosis in patients with cervical cancer depends on the disease stage Five-year survival for different stages are IA-90-100\%, IB- 80-90\%, IIA- $75 \%$, IIB-50-60 \%, IIIA-IIIB 20-40 \%, IVA-IVB-5-10\%. Lymph node involvement has emerged as the single most important determinant of adverse prognosis, even more than FIGO stage. The importance of Lymph node status is starkly illustrated by the observation that even among Stage-IB patients, while the $5 \mathrm{yr}$ overall survival was $88 \%$ among nodenegative patients; it reduced to $40 \%$ among node positive patients. Among stages IIB-IVA, 5-year overall survival was observed to be $57 \%, 34 \%$ and $12 \%$ among patients with node-negative, pelvic-node positive and para-aortic node positive statuses respectively. Increasing bulk increases complexity of treatment. Increasing tumour volume is associated with higher probability of Lymph node involvement, distant-metastasis, pelvic- recurrence and poorer survival, even within patients grouped into the same FIGO-stage.

Overall treatment time is considered to be an independent prognostic factor. Eifel et al (1999) concluded that better results are achievable when the treatment is completed in 8 weeks or less (56 days), which is the time frame that is maximally efficacious and represents an acceptable treatment duration. Loss of local control after exceeding overall treatment time is rather dramatic, with an expected $1 \%$ decrement in local control for every additional day beyond 56 days. Avoid undue toxicities to cause treatment breaks. Avoid breaks as far as possible. Several biological markers are prognostic factors and affect the treatment outcome. Tumour hypoxic tumours fared worse after radiation therapy and exhibit high risk features. Interstitial tumour pressure, VEGF (vascular endothelial growth factor), cadherins, and CD44 are associated with poor survival. Other factors like c-Myc, p53 and p27 also affects survival and acts as prognostic factors. The treatment of cervical cancer varies with the stage of disease. Concurrent Chemoradiotherapy (CCRT) is now the preferred treatment for more advanced stages of disease (I b-II b, III, and IV a). Stage I and II a tumour can be treated surgically or with radiotherapy, with a five-year survival rate of 80 to 90 percent. 15 In patients with disseminated disease, chemotherapy or radiation provides symptom palliation.

We wanted to assess role of tumour size in treatment outcome in carcinoma cervix. 


\section{METHODS}

Prospective observational study of forty patients of carcinoma cervix were analysed who were treated in the department of radiotherapy at SRMS, Bareilly. Study Duration was July 2014 to June 2016 after obtaining permission from the Institutional Ethics Committee. Inclusion criteria includes biopsy proven cancer cervix, Age above 18 years, Karnofsky performance scale above 70, stage IA to IIIB, no history of previous malignancy, Hepatic, renal and cardiopulmonary functions were adequate. Exclusion criteria includes Carcinoma of the cervix FIGO stage IV patients, Metastatic disease, any previous pelvic surgery, any previous chemotherapy, previous pelvic radiotherapy.

Diagnostic evaluation includes Complete medical and physical examination including bimanual pelvic and rectal examination, cervical biopsy, Baseline Haematological test (Haemogram, renal function test and liver function test), Chest radiography, Ultrasound Abdomen or CECT Abdomen and pelvis (Whichever is feasible), Cystoscopy and proctosigmoidoscopy (Only if clinically indicated). All patients were planned and delivered by 3- Dimensional Conformal radiotherapy using four field box technique. Radiotherapy dose delivered to pelvic area was 50 Gy in 25 fractions at $200 \mathrm{cGy} /$ day. This was followed by intracavitary brachytherapy either 4 applications of $6 \mathrm{~Gy} /$ fraction or 3 applications of $7 \mathrm{~Gy} /$ fraction each as per departmental protocol. Total duration of the treatment is less than 8 weeks. Patients received cisplatin $35 \mathrm{mg} / \mathrm{m}^{2}$ weekly intravenous for a total of 5 cycles or $75 \mathrm{mg} / \mathrm{m}^{2}$ triweekly intravenous for a total of 2 cycles. During chemotherapy administration patients were adequately hydrated with 2-2.5 litres of I.V. fluids and supplemented with inj. KCL, inj. MgSo4 and inj. MVI. Radiotherapy was delivered within $1 \mathrm{hr}$. of administration of cisplatin. Proper antiemetic therapy with $5-\mathrm{HT}_{3}$ antagonist, dexamethasone, and ranitidine was given prior to chemotherapy administration. Clinical response was assessed (As per WHO criterion) during radiotherapy and every month after radiotherapy for at least 6 months.

Patients were assessed for objective tumour response as per WHO criteria as follows-

1.Complete Response (CR): Total tumour regression for at least 4 weeks.

2.Partial Response (PR): $50 \%$ or more reduction in product of two major perpendiculars of the measurable tumour for at least 4 weeks.

3.Stable Disease (SD): Less than $50 \%$ or more reduction to less than $25 \%$ increase in cross product.

4.Progressive Disease (PD): Growth of measurable tumour by $25 \%$ or more or appearance of new lesion.

\section{Statistical Analysis}

Collected data was analysed using standard statistical methods (Chi Square test) and software to calculate level of significance using "p" value. Statistical significance considered with $\mathrm{p}$-value of $<0.05$.

\section{RESULTS}

At end of 6 months, outcome of treatment of patients were analysed in terms of WHO response criteria. In our study out of total of 40 cases studied, $75 \%$ (30/40) of patients had complete response, $20 \%(8 / 40)$ had partial response and $5 \%$ $(2 / 40)$ of patients had progressive disease.

\begin{tabular}{|c|c|}
\hline Outcome of Treatment & No. of Patients, n (\%) \\
\hline Complete response & $30(75)$ \\
\hline Partial response & $8(20)$ \\
\hline Stable disease & - \\
\hline Progressive disease & $2(5)$ \\
\hline Table 1. Outcome of Treatment of Patients at the End of 6 Months
\end{tabular}

Table 1. Outcome of Treatment of Patients at the End of 6 Months

In this study, residual was observed in only one patient with volume of disease $<4 \mathrm{~cm}$ (in greatest dimension). While in patients with volume of disease $\geq 4 \mathrm{~cm}$ residual was observed in $36 \%(9 / 25)$ of patients at end of 6 months after treatment. This difference in volume of disease for residual is statistically significant $(\mathrm{p}=0.038)$.

\begin{tabular}{|c|c|c|c|}
\hline $\begin{array}{c}\text { Greatest } \\
\text { Dimension }\end{array}$ & $\begin{array}{c}\text { Total Number } \\
\text { of Patients }\end{array}$ & $\begin{array}{c}\text { No. of Patients Disease Free } \\
\text { at 6 Months Follow Up, n (\%) }\end{array}$ & p Value \\
\hline$<4 \mathrm{~cm}$ & 15 & $14(93)$ & \multirow{2}{*}{0.038} \\
\hline$\geq 4 \mathrm{~cm}$ & 25 & $16(64)$ & \multirow{3}{|c|}{ Table 2. Volume of Disease vs Response at 6 Months } \\
\hline \multicolumn{3}{|c|}{} \\
\hline
\end{tabular}

\begin{tabular}{|c|c|c|c|}
\hline $\begin{array}{l}\text { Alvarez et al 1991 } 174 \\
\text { (Tumour Size) }\end{array}$ & Stage I B & Survival (\%) & p Value \\
\hline $1.1 \mathrm{~cm}=$ & & 88 & \\
\hline $2.1-3 \mathrm{~cm}=$ & & 67 & \\
\hline $3.1-4 \mathrm{~cm}=$ & & 56 & $<.0001$ \\
\hline Eifel et al $1999175^{*}$ & Stage IB & & \\
\hline$<3 \mathrm{~cm}$ & & 88 & \\
\hline $3-5.9 \mathrm{~cm}$ & & 64 & \\
\hline$\geq 6 \mathrm{~cm}$ & & 45 & $<0.002$ \\
\hline Eifel et al $2009176^{* *}$ & IB \& II & & \\
\hline$\leq 4 \mathrm{~cm}$ & & 85 & \\
\hline $4.1-6 \mathrm{~cm}$ & & 69 & \\
\hline$\geq 6 \mathrm{~cm}$ & & 52 & \\
\hline Delgado et al 1681989 & IB-II & 3yr survival & \\
\hline$<3 \mathrm{~cm}$ & & 86 & \\
\hline$>3 \mathrm{~cm}$ & & 68 & $<0.0001$ \\
\hline In present series & IB-IIIB & DFS (6 months) & \\
\hline$<4 \mathrm{~cm}$ & & 93 & 0.038 \\
\hline$\geq 4 \mathrm{~cm}$ & & \begin{tabular}{|l|l}
64 \\
\end{tabular} & \\
\hline \multicolumn{4}{|c|}{ Table 3. Multivariate Analysis of Tumour Size and Prognosis } \\
\hline
\end{tabular}

According to Toita et al, 15 in a review of 70 patients with stage IIB and IIIB carcinoma of the uterine cervix treated with RT alone, reported no significant correlation of 5-year DFS with size of the cervical tumour $<40 \mathrm{~mm}(70 \%$ to $85 \%)$; however, in patients with tumour $>40 \mathrm{~mm}$, the 5-year DFS was $28.6 \%$. Delgado et al ${ }^{16}$ found the $3 \mathrm{yr}$., disease free survival (DFS) to be $95 \%$ for occult tumours, $86 \%$ for those

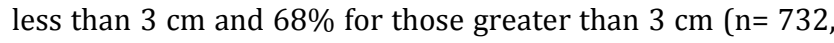
$\mathrm{p}<0.0001)$. Eifel et al $(1999,2009)^{17,18}$ also found similar results. In a study of Daisuke Endo et al,19 retrospectively reviewed records of 85 patients, tumour diameter $>6 \mathrm{~cm}$ was significantly and independently related to poor outcomes. In a study of Da Yong Lee et al $^{20}$ tumour size $\geq 2 \mathrm{~cm}$ (133 vs. 47 months, $p=0.002$ ) was shown to be poor prognostic factor. In the present series, residual was observed in only one patient with volume of disease $<4 \mathrm{~cm}$ (In greatest dimension). While in patients with volume of disease $\geq 4 \mathrm{~cm}$ residual was observed in $36 \%$ of patients. This difference in volume of disease for residual is statistically significant $(p=0.038)$. Thus, 
it states that greater the tumour size poorer is the outcome. It is in correlation with the Eifel et al study and Da Yong Lee et al study. Laila Nuranna, ${ }^{21}$ conducted a retrospective cohort study which enrolled 447 cervical cancer patients, stated that tumour size did not influence overall survival rate.

\section{DISCUSSION}

In cervical carcinoma inspite of best possible treatment a large number of cases present with local pelvic failure. Various attempts have been done to find out the prognostic factors in order to improve the survival by surgery alone, surgery combined with radiotherapy, radiotherapy alone, chemo radiotherapy, chemo radiotherapy plus targeted therapy. Several studies evaluate prognostic factors in carcinoma of cervix. These have been divided into 1) patient related 2) tumour related and 3) treatment related factors. Patient related factors are - age and blood haemoglobin level. Tumour related factors are- stage, lymph node involvement, parametrial extension, histology, grade, hydronephrosis and size of tumour. Treatment related factors are duration of treatment and total radiation dose and concurrent use of chemotherapy. In early stages most data in literature is on the influence of histopathological factors on survival that correlate outcome of radical surgery with features of pathological specimen. Among those indicated are tumour size, depth of stromal invasion, parametrial extension, number and level of nodes involved. Since a significant proportion of early and late stages of cancer cervix are treated with radiotherapy, treatment decisions are often made without these factors taken in cognizance. Present study evaluates the significance of tumour size in treatment outcome of carcinoma cervix.

\section{CONCLUSIONS}

Tumour size in patients of cancer cervix appeared to be one of the strongest factors to impact on disease free survival in the present study.

\section{REFERENCES}

[1] GLOBOCAN 2018, International Agency for Research on Cancer.

[2] GLOBOCAN 2008, International Agency for Research on Cancer.

[3] Nandakumar A, Ramnath T, Chaturvedi M. The magnitude of cancer cervix in India. Indian J Med Res 2009;130(3):219-21.

[4] WHO cervical cancer summary reports update, September 15, 2014.

[5] Henriksen E. The lymphatic spread of carcinoma of the cervix and of the body of the uterus, a study of 420 necropsies. Am J Obstet Gynecol 1949;58(5):924-42.

[6] Geetha KK, Sudhakar G, Ramesh M, et al. Prognostic factors in cervical cancer: a hospital-based retrospective study from Visakhapatnam City, Andhra Pradesh. J Life Sci 2010;2(2):99-105.

[7] Agarwal S, Malhotra KP, Sinha S, et al. Profile of gynecologic malignancies reported at a tertiary care center in India over the past decade: comparative evaluation with international data. Indian J Cancer 2012;49(3):298-302.

[8] Eifel PJ, Berek JS, Makman M. Cancer of cervix, vagina and vulva. In: Devita VT, Hellman S, Rosenberg SA, eds. Cancer: Principles and practice of Oncology. $8^{\text {th }}$ edn. Philadelphia, PA: Lippincott Williams and Wilkins 2008: p. 1496-543.

[9] Baalbergen A, Ewing-Graham PC, Hop WC, et al. Prognostic factors in adenocarcinoma of the uterine cervix. Gynecol Oncol 2004;92(1):262-7.

[10] Farley JH, Hickey KW, Carlson JW, et al. Adenosquamous histology predicts a poor outcome for patients with advanced-stage, but not early-stage, cervical carcinoma. Cancer 2003;97(9):2196-202.

[11] National Comprehensive Cancer Network. NCCN Practice Guidelines in Oncology: Cervical Cancer Version 1.2012.

[12] Rutledge FN, Mitchell MF, Munsell M, et al. Youth as a prognostic factor in carcinoma of the cervix: a matched analysis. Gynecol Oncol 1992;44(2):123-30.

[13] Hill RR, Bush RS, Yeung P. The effect of anemia on the fraction of hypoxic cells in experimental tumour. $\mathrm{Br}$ J Radiol 1971;44(520):299-304.

[14] Bush RS. The significance of anemia in clinical radiation therapy. Int J Radiat Oncol Biol Phys 1986;12(11):2047-50.

[15] Toita T, Nakano M, Higashi M, et al. Prognostic value of cervical size and pelvic lymph node status assessed by computed tomography for patients with uterine cervical cancer treated by radical radiation therapy. Int J Radiat Oncol Biol Phys 1995;33(4):843-9.

[16] Delgado G, Bundy BN, Fowler WC Jr, et al. A prospective surgical pathological study of stage I squamous carcinoma of the cervix: a Gynecologic Oncology Group Study. Gynecol Oncol 1989;35(3):314-20.

[17] Eifel PJ. Concurrent chemotherapy and radiation: a major advance for women with cervical cancer. J Clin Oncol 1999;17(5):1334-5.

[18] Eifel PJ, Jhingran A, Levenback CF, et al. Predictive value of a proposed subclassification of stages I and II cervical cancer based on clinical tumour diameter. Int J Gynecol Cancer 2009;19(1):2-7.

[19] Endo D, Todo Y, Okamoto K, et al. Prognostic factors for patients with cervical cancer treated with concurrent chemo radiotherapy: a retrospective analysis in a Japanese cohort. J Gynecol Oncol 2015;26(1):12-8.

[20] Da Yong L, Chong C, Lee M, et al. Prognostic factors in neuroendocrine cervical carcinoma. Obstet Gynecol Sci 2016;59(2):116-22.

[21] Nuranna L, Prastasari R, Sutrisna B, et al. Survival of cervical cancer patients and its prognostic factors at Cipto Mangunkusumo Hospital, Jakarta. Med J Indones 2014;23(3):163-8. 